\title{
Training to Serve Unmet Surgical Needs Worldwide
}

\author{
Presenters: Robert JW Blanchard, MD, MS(SURG), FRCSC, FACS; Ronald C Merrell, MD, FACS; \\ Glenn W Geelhoed, MD, DTMH, MPH, FACS; Olajide O Ajayi, MBBS, FRCS(ENG), FACS(HON); \\ Donald R Laub, MD, FACS; Edgar Rodas, MD, FACS
}

\section{Global Surgical Need in an Education Context}

Failure to Meet Surgical Needs

An Educator's Perspective: Curriculum,
Resources, and Tools

\section{Examples of Appropriate Training: Model I- Cross-Cultural Training Teams}

\section{Examples of Appropriate Training: Model II- Mobile Surgery}

\section{Panel Discussion and Input from the Audience}

In 1999, our world's population passed the six billion mark. An estimated one-third to one-half of our world's population-2 to 3 billion people—still lack basic surgical care! In this paper we attempt to address the question, "How best can surgical needs be met in a sustainable manner within resources available for training in less-developed populations?" Our goal is to raise awareness of the enormous unmet needs for surgical care in less-developed regions and to suggest ways in which Fellows of the American College of Surgeons may assist in helping meet the needs. In many developing countries, surgical training programs are patterned after North American or European programs. This tends to encour-

No competing interests declared.

Presented at the American College of Surgeons $86^{\text {th }}$ Annual Clinical Congress, Chicago, IL, October 2000.

Panel was sponsored by the International Relations Committee of the American College of Surgeons.

Received May 25, 2001; accepted June 4, 2001

From the Department of Surgery, University of Manitoba, Winnipeg, Canada (Blanchard); the Department of Surgery, Virginia Commonwealth University, Medical College of Virginia, Richmond, VA (Merrell); the Department of Surgery, George Washington University, Washington, DC (Geelhoed); the Department of Surgery, University College Hospital, Ibadan, Nigeria (Ajayi); the Department of Surgery, Stanford University, Palo Alto, CA (Laub); and the Department of Surgery, Medical School of Cuenca, Cuenca, Ecuador (Rodas).

Correspondence address: Robert JW Blanchard, MD, 673 Waverley St, Winnipeg, MB, Canada R3M 3K8. age subspecialization and might not produce surgeons adequately trained to manage the broad spectrum of surgical needs for which people attend their local district hospitals. A complete roster of surgical specialists cannot be made available in most district hospitals throughout the world. So surgeons serving in these hospitals require training and experience that encompass a broader range of surgery than is provided by the usual programs for training general surgeons.

We will describe the needs, define the spectrum of surgery in most district hospitals, and outline some affordable and innovative options for surgical care. Our emphasis is on training and sustainability.

\section{Global Surgical Need in an Education Context}

Robert JW Blanchard, MD, MS(SURG), FRCSC, FACS

Surgeons set the agenda for surgical training and surgical care throughout the world. We may not always get it right, and that is why we should review these issues. Part of the problem is that surgeons like to pursue the more complex technologies and specialization. This pursuit does not match the needs in many parts of the world because in less-developed regions there are far too few surgeons to care for the populations' needs, let alone pursue advanced technologies. Rural Ethiopia, Tanzania, Mozambique, and many other countries and regions have less than $1 \%$ of the number of surgeons that Canada has per unit population. This severe lack of surgeons results in a corresponding lack of surgical care provided to the population. For example, using the most conservative estimates, more than $90 \%$ of women requiring cesarean section do not receive this essential operation in parts of Pakistan ${ }^{1}$ and much of Eastern Afri$\mathrm{ca}^{2}$ Many women unable to receive cesarean section die in childbirth, often from rupture of the uterus. Their babies all die.

The agonies and complications of benign prostatic hypertrophy are shared by men around the world but in 


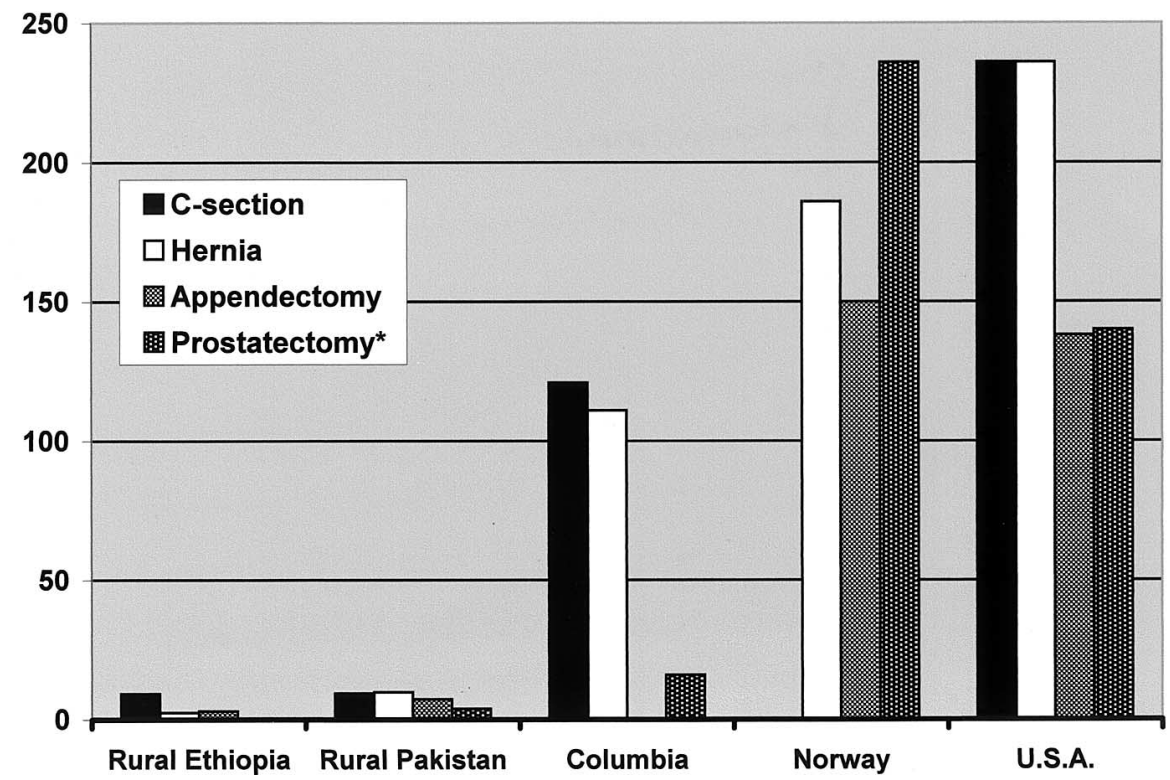

Figure 1. Rates of operations per 100,000 population in rural Ethiopia, ${ }^{8}$ rural Pakistan, Colombia, Norway, and the US. ${ }^{1}$ Data for some operations are not available for some countries. *Prostatectomy per 100,000 men in Norway, per 100,000 total population in the other countries.

many countries, most men suffering from this problem find no relief and some still die from obstructive uropathy. Many people are still dying of untreated acute appendicitis 115 years after Kroenlein, Fitz, and McBurney separately described its surgical cure. Data for trauma are sparse, but there is much to indicate that an already bleak situation is deteriorating.

Although the health systems in North America and Western Europe are able to offer more, and increasingly sophisticated, specialized surgical care, many of our world's populations have no access to care for even the most common surgical illnesses.

The bar graph in Figure 1 displays the disparity between the surgical "haves" and "have nots" for hernia repair, cesarean section, appendectomy, and prostate surgery. The graph also shows that there is a graduated supply of surgical care throughout the world. This indicates a need to direct remedies in a manner tailored to local situations.

Without a doubt, there is a desperate lack of surgical care in much of our world. For the past century, churches and missionary societies have initiated medical and surgical care and training facilities in many parts of the world and continue to do so. But the needs are growing everywhere. We could declare that this is a problem for governments and health agencies to solve. But surgeons in all countries can help to bring about improvement in the availability of basic surgical care. Fellows of the American College of Surgeons can play an important role through encouragement, advice, planning, and direct participation. Without strong input from surgeons, governments can do little or do unhelpful things. An important area for involvement by surgeons is in the realm of surgical training. The present approach to surgical training aggravates the unmet surgical needs in many parts of the world, because general surgeons are not being trained to meet the bulk of surgical problems. This deficiency is one that surgeons everywhere can help improve.

What is not helpful in many deprived regions is for surgeons from advantaged countries to descend briefly with a load of equipment to demonstrate a few highly technical operations that cannot be reproduced or maintained in the region visited. This creates a sense of inadequacy on the part of the local surgeons and their patients. A better approach is to encourage the local surgeons to provide the best possible care within resources that can be sustained.

What training should be provided? A detailed survey of district hospitals in remote rural Pakistan documented the spectrum of surgery carried out in hospitals far from specialized care. ${ }^{1}$ In 19 district hospitals 52 doctors performed almost 24,000 operations in one year. An important finding was that there were only 98 


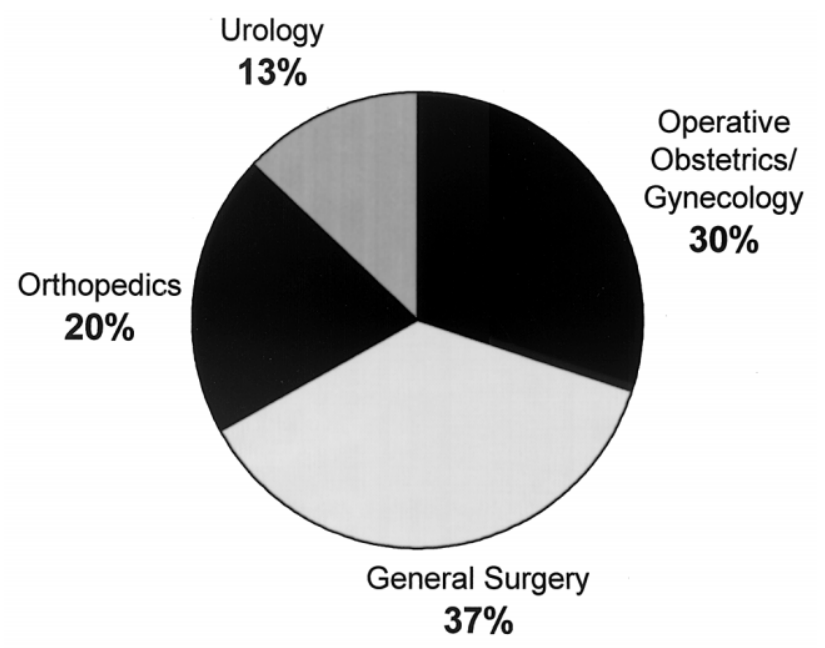

Figure 2. Breakdown of the number of operations by specialty in District Hospitals of Pakistan.

different categories of operations. This is a manageable scope for basic training. Less than half the patients $(37 \%)$ required operations included in current general surgery training programs! Thirty percent of the operations were operative obstetrics or acute gynecology. Simple orthopedics accounted for $20 \%$ and basic urology 13\% (Fig. 2). A general surgeon can manage this scope of surgical cases comfortably if he or she receives broadbased training that includes operative obstetrics, acute gynecology, hot orthopaedics, and basic urology along with the general surgery. Unfortunately, general surgery training programs in Pakistan were much like those in North America and did not provide the broader scope of training required in the district hospitals. The same narrow scope of general surgical training is common in many less developed countries.

In each population, decisions should be made regarding whether to transport all of the patients to large multispecialty centers or to provide care in regional centers with suitably trained surgeons. Issues such as distances, transportation facilities, surgical facilities with staff, and relative costs will assist in making these decisions.

Whatever systems may be devised for the varied needs of different regions, the following principles should be followed:

1. Surgical care must be effective and safe.

2. Surgical care must be widely accessible, either by transport systems or by regional centers.

3. Surgical care must be affordable within the local and national capacity.
4. Surgical care must be appropriate for local situations: infrastructure, such as supply of electricity, communications, available laboratory and pharmaceutical capacity, and so forth have to be considered in planning.

5. The surgical care system must be locally sustainable. Repeated provision of services by external visiting surgical teams can be extremely helpful, but should not take the place of permanent and affordable local programs.

\section{Failure to Meet Surgical Needs}

Glenn W Geelhoed, MD, DTMH, MPH, FACS

Surgery inspires confidence in the professional who keeps the idea of healing as broad as possible. Some still argue that surgery has no role in health care in developing countries because it is an extremely labor- and costintensive investment in one individual at a time. The devalued contention is that the focus should rather be on prevention. But acceptance of prevention programs by a population rests on the credibility won by curative care.

One need not travel to less-developed countries to experience "Third World" health problems. Many parts of our developed world have health concerns more in common with those of developing countries. A number of health care professionals who have never left North America have a great deal of "Third World" experience; for example, in sections of Chicago or Anacostia in Washington, DC. Parts of Harlem in New York share more with the katchi abadis (squatters' districts) of Karachi than with advanced capital centers of the world. Many extremely poor countries have been dealing with health problems using far fewer resources than are available in the US. So, in humility, we can ask of them, "What can we learn from you?" People in such places recognize that they have insufficient money so they must be innovative and imaginative. So the question is, "What can we do today to learn how we might help specific needy populations?" For example, perhaps the biggest health care resource in some parts of Nigeria might be a road to get people to the nearest hospital.

What, if any, roles may North American surgeons fill in going "there" and trying to help? One advantage medical personnel have is that the discipline is readily translatable into other cultures: anatomy and physiology stay the same. This is not true for lawyers, accountants, or business people. Surgery is highly regarded everywhere because it provides immediate relief for many illnesses. Medical education in most countries uses the English 
language, so there are fewer obstacles to surmount for English-speaking teachers. Teaching that will produce new teachers in a sustainable way can provide lasting benefits.

One of the obstacles is the lack of facilities, including electrical power and plumbing, to say nothing of endoscopes, CT scanners, etc. Many western surgeons have difficulty imagining how to function without these "necessities" despite the fact that surgery has been practiced effectively for generations in their absence. In America there may be competition for patients among provider groups or even surgeons. But in much of the world, there are so few doctors that no competition exists for surgeons willing to provide affordable care. Surgeons going from the West to poor regions often face surgical challenges they have never seen before; for example, the need to perform a cesarean hysterectomy. Surgeons from the West also learn from their Third World colleagues how to handle bigger problems with fewer resources in much larger and sicker populations. In order to ensure that surgical care programs are sustainable, it is important to fashion the responses to needs through local indigenous resources. While adhering to basic principles, it is possible to simplify many of the essential components: sterilization can be done in a pressure cooker, adequate lighting can be powered by solar panels supplying automobile headlamps, homemade items can be recycled for repeated reuse.

\section{Mind the gap}

Travelers on the London underground railway periodically hear the warning, "Mind the gap." In this "golden age of surgery" the gap is widening between "haves" and "have nots" in all parts of the world. Does anyone mind? In sub-Saharan Africa only one of 15 women needing cesarean section have access to any health care personnel. ${ }^{2}$ In many countries, such as Mozambique, the present needs are such that enough trained physicians and surgeons simply cannot be supplied within many years, if ever. Even if a dozen medical colleges could suddenly appear, the supply of surgeons would not meet the needs for decades. What can be done in the meantime and in the absence of sufficient medical trainees? In parts of Congo and Mozambique nurses or technicians are the only "surgeons" available. With appropriate training, guidelines, and supervision these workers provide good surgical care, within the scope of their capacities, where otherwise no surgical help would be avail- able. These surgical technicians competently manage common procedures such as hernia repair, drainage of abscess, and cesarean section. In Mozambique, such a trained technician is called a técnicos de cirurgía (assistant medical officer). These technicians are trained intensively for 3 years to provide surgical care for a variety of problems including abscesses, uterine curettage, cesarean sections, appendicitis, intestinal perforations, and strangulated hernias. ${ }^{3}$ Twenty such technicians had been deployed in rural regions of Mozambique before 1999 with an average of 700 operations each per year. Is this a return to the era of "barber-surgeon" and surgical mayhem? Such a program could result in disasters if not properly organized and supervised. In fact, the outcomes of the surgical care by the técnicos de cirurgía has approximated that of the central hospital. ${ }^{4}$ Operative mortality rates have been $0.4 \%$ and $0.1 \%$ for emergency and elective operations, respectively. In other countries and regions, similar alternate arrangements have functioned well and provided much relief from morbidity and mortality that would otherwise not be provided at all.

What can we in the American College of Surgeons do? Our very awareness of the care disparity inspires hope among beleaguered surgical colleagues in other lands. It is clear that something more must be done to provide surgical care to the huge populations that, at present, have no surgical care at all. The important change is that the lack of surgical care in the Third World is now on the agenda and we can continue to discuss and wrestle with how best to provide help for the unmet needs.

\section{An Educator's Perspective: Curriculum, Resources, and Tools}

Olajide O Ajayi, MBBS, FRCS(ENG), FACS(HON)

To satisfy unmet surgical needs worldwide, the perspective of the educator in the training of a surgeon is the sum of four goals. They are:

1. selection of appropriate candidates for training;

2. setting of standards for course contents and the duration of training;

3. provision of effective methods for the transfer of theoretical knowledge and the acquisition of practical skills; and

4. determination of the end result of these measures through examinations and certification.

The aim in the long term is the emergence of young, innovative surgeons adequately motivated and techni- 
cally competent to execute decisions based on good judgment and sound scientific knowledge. Although the pattern of practice varies with levels of socioeconomic development, the educator's primary focus in differing circumstances is the search for adjustments to satisfy the local realities of means, resources, and tools that will provide appropriate training and enhance access to affordable and effective surgical services.

\section{Curriculum}

A good curriculum in any setting must:

1. reflect the local disease patterns;

2. recognize that geographic pathology is not static

3. enrich clinical experience by expanding the variety and volume of clinical exposure;

4. encourage originality and flexibility by enhancing the reasoning process through didactic teaching, rotating clinical experience, and continuing medical education;

5. promote professional confidence through the acquisition of technical expertise;

6. provide the opportunity to keep abreast of developments elsewhere through personal communication, participation in local and international conferences, and access to selected journals, articles, and monographs;

7. inculcate the spirit of enquiry through research and encourage the critical self-appraisal of performance; and

8. foster the development of team spirit and a sense of commitment to teaching others.

A curriculum so crafted evolves over time even when resources are apparently unlimited. It is seldom an instant creation.

\section{Basic science}

The need to support and develop methods that achieve excellent outcomes in sustainable and affordable ways may require a greater appreciation of the necessity for a wider breadth of basic science knowledge than has been generally recognized.

\section{Basic skills}

The acquisition of basic skills built on sound scientific knowledge that allow for professional self-development and adaptation constitute the core of good training. "Rural surgery," may demand greater skills, experience, and deftness given the scanty facilities available and the limitations of ancillary staff. The broad-based training necessary for service in rural and under-doctored areas includes the acquisition of skills in emergency obstetrics and gynecology, local and regional anesthesia, pediatric
Table 1. Surgical Operations in Eruwa (1983-2000)

\begin{tabular}{lr}
\hline Operation & $\mathbf{n}$ \\
\hline External hernia repair & 4,610 \\
\hline Excision of superficial lumps & 962 \\
\hline Laparotomy for peritonitis & 748 \\
\hline Caesarian section & 534 \\
\hline Hydrocelectomy & 486 \\
\hline Prostatectomy & 278 \\
\hline Intestinal obstruction & 155 \\
\hline Vagotomy and drainage & 95 \\
\hline Orchidopexy & 94 \\
\hline Sequestrectomy & 90 \\
\hline Thyroidectomy & 88 \\
\hline Insertion of chest tube & 71 \\
\hline Major open fracture & 48 \\
\hline Splenectomy & 17 \\
\hline Nephrectomy & 11 \\
\hline Miscellaneous & 200
\end{tabular}

(From a lecture given by OA Awojobi at University College Hospital, Ibadan, Nigeria, September, 2000; with permission.)

surgical emergencies, urology, otorhinolaryngology, some radiology, and ultrasonography. The spectrum of surgical diseases in a typical rural community as illustrated in Table 1 includes the unsolved problem of infections and infestations and the unmet challenges that Anthony Barker aptly described as the surgery of infection and neglect. ${ }^{6}$

\section{New dimension}

The emergence of new Third World pandemics of noncommunicable diseases, such as trauma, cancer, and cardiovascular and renal diseases, continuously adds to the already unmet "old" surgical needs. The combined challenges of the new and the old needs add new complicating dimensions to training in developing countries. A continuing medical education program for the training and retraining of core staff in a surgery unit should be an essential feature of the curriculum.

\section{Management skills}

Other factors that affect the standards of surgical training and practice, particularly in developing countries, include poor or misguided management of scarce resources. Management skills should include strategic planning and evaluation, personnel management, health management information, statistical analyses, financial management and budgeting, social marketing of affordable health care programs, drug and equipment management, medical audit, and quality assurance and control, 
among others. There is no greater justification for evidence-based decision-making than in situations when so much is required with so little to spare.

\section{Resources}

\section{Manpower}

$\mathrm{Du}$ Plessis identified a sound economy as "the primary requirement" in health development. ${ }^{7}$ The need to focus on manpower development is crucial, given the appalling surgeon/patient ratios in nearly all Third World countries. Manpower is more than the availability of doctors or surgeons. A critical mass of health workers is necessary to provide the environment for learning and training. Even then, the available personnel is inappropriately distributed between the urban and rural areas.

\section{Funding}

The persistent underfunding of health care affects the performance and motivation that can be expected from the educator and the extent to which the trained core staff can be retained.

\section{Conceptual failure}

The new emphasis on primary health care complicated the issue of resource allocation within the diminishing resources of Third World countries. It brought with it the misconception of an inexpensive, affordable, accessible, and efficacious health system. A health system was advocated especially for developing countries based on three tiers with a referral system. Surgery suffered greatly in the scheme and layout because of its perceived expensive needs and apparently disproportionate consumption of available resources. The implementation of the primary health care concept is in troubled waters because: it has not reduced the cost of health care or changed the health indicators in most developing nations; it has advocated community participation without recognizing community interests; and it has failed to give practical expression to the holistic concept of health care as illustrated by a tripod, two legs of which have, at best, been immobilized by collapsed economies and the debt burden.

What has yet to be fully appreciated is the extent to which confidence in modern scientific medicine has been undermined and confidence in the primary health care itself lost by the failure to quickly respond to trauma, surgical, obstetric, and other life-saving emergencies, particularly in developing countries.

\section{Tools}

\section{Medical Attendants}

The issue of lower level manpower development in surgery has been extensively debated in developing countries. The choice in many instances has often been between a technician-performed surgical service or none at all. The sum of the depth of feeling among protagonists of lower level manpower is as expressed by Garrido, ${ }^{4}$ who, against a background of Mozambique's doctor/ population ratio of $1: 40,000$ and surgeon/population ratio of $1: 400,000$, wrote:

In under-serviced developing areas, the preeminent concern is the overwhelming need for health care services and the resource constraints that deny medical care to many, in some instances most, of the population. Our responsibility is first to see that services are rendered to the desperately needy, and then to upgrade the quality of those services. In this continuing crisis, with increasing desperation brought on by pressures of a burgeoning African population living and dying in poverty, life-saving expediency using all possible means is a more ethical medical response than professional Puritanism.

But he admitted, "the decision to perform major surgical interventions is frequently more difficult than the intervention itself."

\section{Paramedical staff}

This kind of reasoning is further encouraged by the proved value of nonmedical personnel and general practice physicians trained to perform specific duties in the domain of surgery. The popular example is the experience in Gambia, where nurses were trained initially to extract cataracts under supervision and their skills were upgraded to include lens implantation (Faal $\mathrm{H}$, personal communication, Feb 1999). The acquisition of a single skill, however, does not constitute the art and science of surgery. The general practice physician is not translated into a surgeon by a 6-month program in surgical and obstetric emergency as confirmed by the McGill Ethiopia Community Health Project, which proved unsustainable after the first and only course of training. ${ }^{8}$

\section{Local training}

For some decades, local training programs have emerged in developing countries with the assistance of older and established surgical colleges in the United States, Canada, Europe, Australia, and New Zealand. The advantages included: 
1. the larger number of surgeons that could be trained above what established colleges or institutions could accommodate;

2. the assumed benefit of training in the environment of future practice;

3. the opportunity to upgrade local facilities to meet training needs;

4. the availability of the service of trainees during their period of the training;

5. the control or limitation of the problem of trainees not returning to their countries of origin at the end of training.

The difficulties include:

1. the need to meet globally acceptable minimum standards of training;

2. the lack of sufficient trainers working under suitable conditions;

3. the lack of facilities to meet and sustain locally designed programs and adequate minimum standards;

4. the need to organize and guarantee continuing education programs for teachers and trainees;

5. the inability of most people to pay for services even in the government-owned hospitals.

\section{Specialization}

Specialization is progressing worldwide. The fragmentation of surgery that accompanies specialization may have very limited use in overcoming or reducing the unmet surgical needs in most parts of the world.

\section{Stratification of specialists}

The other tool advocated to meet surgical manpower needs in developing countries is the stratification of the endpoints in training.

The stratification of the endpoints in training programs will have to be handled with care. A downward review of standards to increase the quantity of specialists undermines the value of training and the determination of a credible 'minimum' surgical standard. In a milieu of rapidly changing technology and advancement in the medical sciences, a 'minimum standard' of surgery will need to be defined first. Stratification is socially divisive in concept and diverts attention from issues that need solution. Producing a medical or surgical or nursing 'technician' cheaply, quickly, and superficially has been tried (before) and discarded. ${ }^{?}$

\section{Options}

What then can we consider as the desirable tools to assist? What has been our experience with them?
Travel Fellowships for young surgeons to centers in the developed countries. These have proved invaluable to the few who can benefit. Recipients returning have encouraged and stimulated younger colleagues by sharing their experience and reporting developments in centers visited.

Access to biomedical information through book and journal donations. There is the difficulty in selecting appropriate books and journals. The cost of postage can be considerable.

Assistance in the development of local training programs through short-term clinical teachers and demonstrators. This has been the most visible area of successful intervention. The assistance of the International Federation of Surgical Colleges and the Association of Surgeons of Great Britain and Ireland in the genesis of the West African College of Surgeons is an example. The determination of international standards through the examination processes was facilitated by the nomination and sponsorship of examiners by the Royal College of Surgeons of England in the early stages. By this mechanism, a reciprocity was established at some levels in the diploma awarded by the two colleges. The relationship ceased during the bleak period of the Nigerian dictatorship and can now be resuscitated.

Organization of courses, workshops, seminars, and visiting lectureships. This is widely reported in the Pacific zone and in South America, mostly mediated by the Royal Australasian College and the American College of Surgeons, respectively. The numerical strength of the College chapters in various countries is an important factor in the Americas. Many African colleges, groups, and associations are beginning to look inward in this effort because of the unwillingness of foreign teachers to enter unstable regions.

Provision of appropriate audio-visual teaching and learning aids. The preferred options in this kind of assistance are in the areas of basic and applied sciences. Clinical situations, particularly in operative surgery, are less useful.

\section{Examples of Appropriate Training: Model I-Cross-Cultural Training Teams}

Donald R Laub, MD, FACS

One model that is successfully meeting the need for training initially in plastic surgery and also providing a 
high standard of surgical care is Interplast, an independent foundation. Members have made more than 600 trips to various parts of the world and performed more than 40,000 operations while providing training to local physicians and surgeons. This model is based on five principles:

1. Humanitarianism can be compatible with educational goals and, in fact, humanitarianism ought to be taught as an educational goal.

2. Foundations (US 501.C.3) are effective means for such humanitarian service and useful partners with universities. Some benefits include the fact that foundations can assume the liability for foreign programs that universities are becoming chary of assuming. Additionally, separate fundraising is possible along with the pride of ownership that occurs when a foundation helps a university.

3. Internationalization of surgical teams and the training of residents is an important goal. Representatives of two, three, or more countries multiply ideas and innovations.

4. Recipients become providers. Providers teach recipients in one country who then, in turn, become providers and teachers, often in a third country, and so on.

5. A curriculum based on "task achievement" outcome works better than a "time in service" approach.

Interplast was established as a foundation to meet the training needs of Stanford University residents, and it evolved to meet the surgical needs of developing countries but with humanitarian motivation. The program then began to provide role models for trainees of both America and the developing countries involved. The final evolution was to mount educational programs. The educational programs flowed from the motivation of a surgeon to help people and to teach. Powerful psychic income occurs in fulfillment of the reason why we became physicians in the first place-the "doctor instinct." A professional is one who applies his or her skills for the benefit of others. The good feeling that this produces is the psychic income that becomes the motor driving the programs.

In this model, there are two primary teaching goals. The first is to develop psychomotor skills, ie, how to do operations. This takes 2 years. The second goal is to develop an attitudinal behavior change, which takes place over 5 years. Two additional benefits occur: recipients become providers and teachers, and lifelong professional relationships are developed. There are two models: one for teaching in university hospitals and the other model for district hospital-level surgery. The following outlines the basic district hospital model: Intermittent trips, or monthly or quarterly rotations, depending on the specialty; a team of
4 to 12 visiting professionals, each with a counterpart from the host country; and a serious commitment to curriculum on everyone's part.

Intermittent trips allow participation of busy professionals. The team achieves more than a single surgeon could do. The team reaches a high level of achievement similar to that of an athletic team accomplishing what they have not done before. The experience of working in a team is greatly appreciated by the participants along with the satisfaction of achieving something worthwhile.

An advantage of the foundation-university relationship is the ability of the foundation to provide liability insurance, community support, and background funds. The university provides the staff, skills, and young, idealistic trainees. It is possible to acquire team members from several countries, bringing a wealth of additional experience and widening each member's friendships. In addition, the teams are multiprofessional and include nurses, anesthesiologists, pediatricians, surgeons in various specialties, and technicians.

The curriculum of the district surgeon consists of parts from many specialties. The curriculum is divided into tasks or operations as needed and requested by the trainee hosts. These tasks are filtered and selected depending on whether a particular task is considered to be teachable by the providers.

The following is a brief outline of the district surgery curriculum:

General surgery: Trauma; laparoscopy; wound care; secondary level general surgery

Orthopaedics: Fractures; club foot; bone healing

Plastic surgery: Burns; repair of lacerations; cleft lip repair

ObGyn: Childbirth; dilation and curettage; infections

Community health: Principles

Neurosurgery: Epidural and subdural hemorrhage

An example is shown for ENT: facial fractures (Table 2). When all the boxes are marked as completed, the trainee is declared competent in facial fractures. There is a similar sheet for every task or operation.

An important question arises as to whether infrastructure aid should be provided from the outside to augment sustainable local resources. This needs careful evaluation for each situation. Great caution should be exercised concerning the provision of bricks and mortar.

This program has demonstrated the benefits of crosscultural cooperation and assistance. Medicine has no 
Table 2. Task Achievement System for Facial Fractures

\begin{tabular}{lllcccc}
\hline Facial fracture & Anatomy & Reading & Video & See & Do & Evaluation \\
\hline Bone plate fixation & Gray's & & Yes & Yes & Yes & Do operation, observed \\
\hline Selection of incisions & Professor & & Yes & & Quiz & Quiz \\
\hline Dental occlusion & Model & & Yes & Yes & Yes & Quiz \\
\hline Nasal fracture & Gray's & & & & Yes & See work \\
\hline Mandible fracture & & Chapter & Yes & Yes & Yes & Do operation, observed \\
\hline Open frontal sinus & & Chapter & Yes & Yes & Yes & .
\end{tabular}

political boundaries, and the "doctor instinct" is conducive to helping others. Money becomes a secondary motivator. The advantages of nonprofit foundations have been demonstrated as a good option for this type of program. It allows pride of ownership and benefits the university through collaboration. Participants learn how to be happy without money or advanced technology; they develop lifelong professional relationships; they participate in humanitarianism as role models for the trainees.

Somos bueyes eb la misma yunta (We're all oxen pulling the same yoke). Los barcos son seguros en los puertos, pero no fueron hechos para estar alli (Boats are safe in the harbors, but they weren't made to be there).

\section{Examples of Appropriate Training: Model II-Mobile Surgery}

Edgar Rodas, MD, FACS

The term unmet surgical needs has connotations that vary depending on where you are. In America it could mean lack of the latest technical machines or lack of the exceptionally skilled surgeon performing extremely sophisticated operations. In many parts of the world, unmet surgical needs is a matter of life and death for hundreds of thousands of people.

I received a call one night some years ago from a small town in the mountains. A young pregnant woman with severe abdominal pain had arrived there after 6 hours on horseback. There was no surgeon in the town so I traveled 6 hours by car and 3 more hours on horseback only to find a young woman dead along with her dead unborn child. Figures help our minds to understand the problem; experiences make our hearts understand the problem and can change one's life. There is a huge gap in the availability of care, and the gap is widening. On one hand, we have conquered space and deciphered the genetic code. On the other hand, thousands of women and children are dying because they have no access to timely surgical care.

The majority of people live in rural areas and small towns often with no roads or with almost impassable roads. On the other hand, in the same developing world, there are large and modern cities. The differences are startling. A surgeon going from the US to conferences in some developing countries may get the wrong impressions. He or she will see beautiful presentations in impressive facilities with state-of-the-art equipment, including robotics and binocular videosurgery. Unfortunately, these facilities serve a small fraction of the population.

Because much of the population cannot travel to the surgical facilities, we have envisaged and developed a program of mobile surgery. Initially we faced objections and criticisms including concern about infections, lack of blood transfusions, and so forth. In fact, it is recognized that nonhospital bacteria are less resistant to antibiotics than hospital acquired organisms. Blood transfusions are required extremely infrequently. Subsequent analysis of outcomes has laid the objections to rest.

We built an operating room in a 24-foot van (Fig. 3). A larger truck could not negotiate the narrow winding Andean roads in Ecuador. It contains a small operating room with adequate lighting, anesthesia equipment, electrosurgical unit, and basic monitoring instruments. Another room is for the surgeons to scrub and for storing

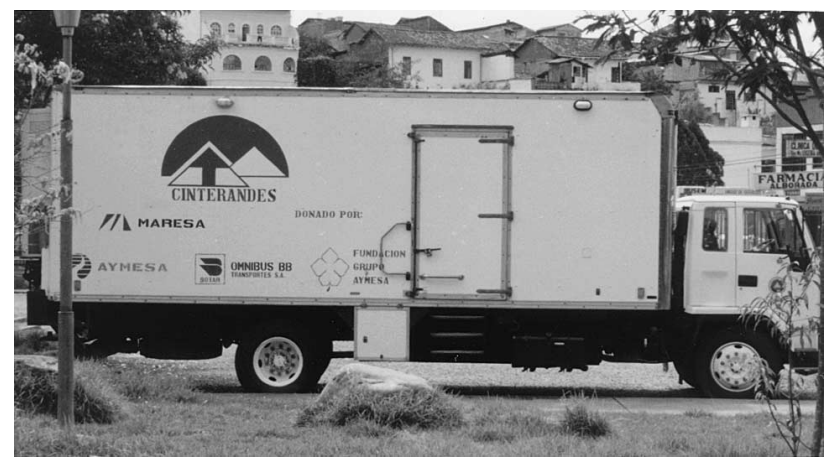

Figure 3. Mobile operating room in a truck in Ecuador. 
Table 3. Number and Types of Operations to the End of 2000

\begin{tabular}{lr}
\hline Specialities & \multicolumn{1}{c}{$\mathbf{n}$} \\
\hline General surgery & 1,373 \\
\hline Urology & 1,092 \\
\hline Gynecology & 438 \\
\hline Reconstructive surgery & 224 \\
\hline Ophthalmic surgery & 95 \\
\hline ENT surgery & 6 \\
\hline Total & 3,228
\end{tabular}

medical supplies. There are two tents, with oxygen, suction, and monitoring devices: one for preoperative preparation and one for postoperative care.

A local doctor performs initial screening of patients. A complete history and a physical examination are performed and informed consent is acquired. On a set schedule the mobile unit sets out to the designated villages and sets up in a suitable location in the village to perform the scheduled operations and any emergency procedures that are required. Sometimes operations are performed in small country hospitals when facilities permit. Locations visited have included sites in the Amazon jungles, coastal lowlands, and high Andean mountain regions. Practical obstacles have included road obstructions from landslides and other unexpected barriers. On one occasion an overhanging rock ledge had to be dynamited to permit the truck to pass.

Beside the provision of essential surgical care that would not otherwise be available, the program includes research, teaching, and telemedicine consultations. The research has demonstrated the effectiveness and safety of this approach and has acquired valuable statistical information. The teaching component has been valuable for both Ecuadorian and foreign students. By the end of the year 2000, more than 3,000 operations were performed in this mobile unit with excellent outcomes. The breakdown of procedures by specialty is shown in Table 3 .

\section{Panel Discussion and Input from the Audience}

\section{Ronald C Merrell, MD, FACS}

Surgeons are concerned about the problem of unmet surgical needs in our world, as demonstrated by the almost 600 Fellows and Residents who filled the auditorium for this panel discussion. The many comments and questions confirmed the conviction that surgeons are "doers" with a great desire to be helpful. Unfortunately, there was insufficient time to deal with the large number of insightful suggestions. Perhaps letters to the editor may pick up some of what we have omitted. Some of the themes that arose during the discussion period are as follows:

Establish a list of resources for service in less-developed countries. This could be published periodically in the Bulletin and added to the ACS Web page.

Provide links in the Web site to organizations involved in needy regions.

Establish a list of activities that the ACS is doing for underserved regions and populations.

Establish a booth for international surgery in the scientific displays at the annual Congress meetings. Invite international organizations to participate.

Develop a register of experienced and available advisers to help develop or design sustainable training programs suitable for needy regions.

Establish an institute or committee for the study of appropriate need-oriented and affordable evidence-based surgical training suitable for various national circumstances.

Establish seminars or colloquia for Third World surgeons to share experiences and techniques for solving surgical problems with innovative inexpensive measures.

Encourage governments and colleges to provide for the main surgical needs before moving to more complex and expensive options.

Establish a clearing-house with advice for surgeons traveling overseas to cover such matters as liability insurance, health needs, malarial and other prophylaxis, and so forth.

Explore options to assist new trainees with managing student loans and other matters to facilitate their involvement abroad.

Promote the establishment in general surgery training programs of a "rural" training stream with a broader scope of experience.

Consider programs to bring patients from unserved regions to North America for surgical care.

Undoubtedly the International Relations Committee will want to consider some of the above suggestions for further development. The needs in our world for surgical care are growing. We can do better so we must do better.

Many organizations and individuals are providing essential surgical care or training in deprived areas of the world. In the past, churches and missionary organiza- 
tions provided most of this activity. More recently, many independent or other novel approaches have been developed to bring care and training where they are most needed. In this article, we describe two novel and innovative approaches to such care and training. We have also touched on the debate concerning the scope of training required for rural surgeons in poor regions. On one hand, Professor Ajayi argues that the rural surgeon is isolated and needs extra training to be able to meet unusual challenges. On the other hand, as Dr Geelhoed points out, there simply are not enough doctors, let alone surgeons, to meet the needs in some countries such as Mozambique. In some countries nonphysicians are trained to perform open surgical procedures. It is reported that the outcomes are good and that the overall benefit supports this approach where there are no doctors. Undoubtedly, there is much scope for innovation, adaptation, and carefully performed research. Outcomes studies and analysis of what situations and operations can be handled adequately by technicians provide a continuing challenge and will help sort out the best options for the varied local needs. Several reports of such studies have already been published. ${ }^{3,10}$ There are numerous opportunities for service where few surgeons go and where training is desperately needed. Fellows of the American
College of Surgeons are involved in many ways toward meeting this important need.

\section{REFERENCES}

1. Blanchard RJW, Blanchard MEE, Toussignant P, et al. The epidemiology and spectrum of surgical care in district hospitals of Pakistan. Am J Public Health 1987;77:1439-1445.

2. Nordberg EM. Incidence and estimated need of cesarean section, inguinal hernia repair, and operation for strangulated hernia in rural Africa. Br Med J 1984;289:92-93.

3. Vaz F, Bergström S, da Luz Vaz M, et al. Training medical assistants for surgery. Bull WHO 1999;77:688-691.

4. Garrido PI. Training of medical assistants in Mozambique for surgery in rural settings. S Afr J Surg 1997;35:144-145.

5. Ajayi OO. The effects of local pathology and disease patterns on the training and practice of surgery. Trans Coll Med S Afr 1987; 31:161-164.

6. Barker EA. Surgical techniques and priorities. Proc R Soc Lond B 1977;199:69-72.

7. Du Plessis DJ. The development of surgery in Southern Africa. In: Cook J, ed. Collected papers (1958-1979). Edinburgh: International Federation of Surgical Colleges. 1982:50.

8. Loutfi A, McLean APH, Pickering J. Training general practitioners in surgical and obstetrical emergencies in Ethiopia. Trop Doctor 1995;25(suppl 1):22-26.

9. Ajayi OO. Surgical training in $21^{\text {st }}$-century Africa. S Afr J Surg 1999;37:1,3-5.

10. White SM, Thorpe RG, Maine D. Emergency obstetric surgery performed by nurses in Zaire. Lancet 1987;12:612-613. 